\title{
O PENSAMENTO EDUCACIONAL DE ÉMILE DURKHEIM
}

Carlos Lucena ${ }^{1}$

\section{RESUMO.}

Este artigo analisa os principais pressupostos de pensamento de Émile Durkheim sobre a sociedade e a educação. Debate com algumas das suas principais obras, entre elas, "A Divisão do Trabalho Social", "O Suicídio", "As Formas Elementares da Vida Religiosa", "Educação e Sociologia", demonstrando os elementos para a construção de uma teoria do consenso social. Proporciona o debate sobre como estas teorias influenciam a educação nos dias atuais.

Palavras-chave: Educação; Positivismo; Durkheim, Pedagogia Tradicional.

\section{THE THOUGHT OF EDUCATION OF ÉMILE DURKHEIM}

\section{ABSTRACT}

This article analyzes the main assumptions of the thought of Emile Durkheim about society and education. Discussion with some of his major works, among them "The Division of Social Work," "Suicide," "The Elementary Forms of Religious Life," "Education and Sociology", showing the elements for building a consensus theory social. Provides discussion on how these theories influence education today.

Keywords: Education; positivism, Durkheim, Traditional Pedagogy.

\section{Introdução}

Émile Durkheim nasceu em 1858 em Epinal, no noroeste da França e faleceu em Paris, no ano de 1917, após a morte de seu único filho, dois anos antes, no front de Salonique, lutando pelo exército francês, durante a $1^{\text {a }}$ Grande Guerra Mundial. Discípulo de Kant e Augusto Conte, sua contribuição foi notável para a consolidação da sociologia enquanto ciência na França. Suas ideias transpuseram as fronteiras francesas, influenciando gerações de políticos, pesquisadores e educadores. A influência na educação através dos pressupostos de pedagogia tradicional, a utilização de seus princípios nas técnicas da produção em massa, bem como a edificação das bases do nazismo, são exemplos da afirmação anterior.

Durkheim entende a educação como uma poderosa ferramenta para a construção gradativa de uma moral coletiva, fundamental para a continuidade da sociedade capitalista. Esse é um pressuposto fundamental para o entendimento de suas preocupações expressa em um grande debate com as ideias liberais presentes na Europa no início do século XX. A crítica ao liberalismo se apresenta com a demonstração da impossibilidade de concretização de uma sociedade mais avançada sob a lógica do individualismo.

O individualismo, entende Durkheim, é o maior inimigo para a constituição e manutenção de uma sociedade das máquinas herdeira da primeira revolução tecnológica. A constituição de uma moral coletiva expressa na divisão social do trabalho manifesta pela solidariedade orgânica é entendida como grande desafio para o avanço de uma sociedade.

Esse debate não se deu ao acaso. Durkheim viveu em um período histórico conturbado, o "olho do furacão", marcado por crises econômicas, crescente urbanização da sociedade e a construção gradativa da Primeira Grande Guerra Mundial, desdobramento 
dos conflitos econômicos das grandes potências mundiais em busca de novos mercados para a troca de mercadorias e acesso a matérias primas. ${ }^{2}$ Esse processo social foi acompanhado pelos desdobramentos da grande crise econômica de 1870, uma crise de superprodução de mercadorias acompanhada do crescimento da miséria, violência e falências de várias empresas.

Os desdobramentos da crise de 1870 proporcionaram fundamentos e aspirações para o desenvolvimento das ideias de Durkheim. Durkheim percebia um futuro incerto da sociedade capitalista, discordando de concepções otimistas, inclusive do seu velho mestre Auguste Comte, que uma sociedade das máquinas avançava e por ela a construção da sociedade mais avançada da história da humanidade. Era um período de intenso debate expresso em diferentes interpretações sobre a crise. Para alguns, ela era exemplo da materialização de contradições inconciliáveis que levariam ao colapso de todo o modo de produção capitalista. Para outros, aos quais Durkheim se inseria, a crise indicava a necessidade de construção de uma moral coletiva, condição fundamental para a manutenção da sociedade da forma como ela era. ${ }^{3}$ As teorias do conflito e do consenso se chocavam apontando caminhos distintos quanto ao futuro da sociedade. ${ }^{4}$

Todo este processo de transformações na sociedade capitalista influenciaram Durkheim e suas preocupações quanto ao futuro da humanidade. Émile Durkheim não era um otimista tal qual Auguste Comte. As marcas da grande crise do capitalismo em sua fase concorrencial de 1870, tal qual afirmamos acima, estavam presentes em suas reflexões. Da mesma forma, os alicerces da Primeira Grande Guerra Mundial construídos no final do século XIX e início do XX, guerra que custaria a vida de seu filho e indiretamente a sua, eram entendidas como sinônimas de desagregação e ausência de moral. A aproximação com os pressupostos kantianos voltados à moral e, principalmente, ao ordenamento social, se baseava nesse contexto.

O sonho de ordenamento kantiano defendido por Émile Durkheim justificava, na realidade, uma sociedade edificada pela lógica da opressão, violência e guerras, pressupostos contraditórios ao princípio da perfeição só possível no "admirável mundo novo". O sonho de uma sociedade em que a história se movimenta pela causa e efeito impulsionada pela construção do consenso social, rígida divisão social do trabalho e moral coletiva. Não foi ao acaso que o Nazismo Alemão, uma vez que condizia com a elaboração de um projeto de homem do presente para o futuro. Esse é o olhar, sem qualquer pretensão de esgotar a discussão em tão poucas páginas, que convidamos o leitor a compartilhar na leitura do pensamento de Durkheim, especialmente com referência à influência em suas reflexões educacionais. Alguns afirmam que seus pressupostos não mais influenciam a sociedade. Outros entendem que não mais se aplicam à educação. $\mathrm{O}$ que pretendemos é recuperar alguns fundamentos de seu pensamento, proporcionando aos educadores, um relacionar com suas práticas no cotidiano escolar, para que juntos encontremos respostas e perguntas.

\section{Alguns pressupostos da obra de Émile Durkheim.}

A contribuição científica de Émile Durkheim para a analise da sociedade foi vasta, abordando diferentes segmentos e processos sociais. As obras "A Divisão do Trabalho Social", "O Suicídio", "As Formas Elementares da Vida Religiosa", "Educação e Sociologia", "Educação Moral", entre tantas outras, foram fundamentais para a construção de uma lógica conceitual voltada ao consenso social.

A Divisão do Trabalho Social, tese de doutoramento de Durkheim, produzida em 1893, foi o seu primeiro grande livro, cujo tema principal debateu a relação entre os indivíduos e a sociedade. Sua preocupação estava em descobrir como os indivíduos 
constituem a sociedade e o consenso em seu interior. Esses são pressupostos que permitiram Durkheim elaborar uma teoria norteiadora de todas as suas reflexões, ou seja, $a$ teoria da solidariedade.

A teoria da solidariedade durkheiminiana se divide em duas: a solidariedade mecânica e a orgânica. Na solidariedade mecânica os homens estão unidos a partir da semelhança de valores expressos na religião, tradição ou sentimento comum. Este é um tipo de solidariedade à qual a sociedade tem coerência porque os indivíduos ainda não se diferenciam. A solidariedade orgânica, por sua vez, é diferente da solidariedade mecânica. Solidariedade orgânica é aquela em que o consenso resulta de uma diferenciação, ou se exprime por seu intermédio. Dentro desta concepção, os homens não se assemelham, sendo diferentes entre si. A união desses homens só é possível a partir da dependência que um tem do outro para realizar alguma atividade social. ${ }^{5}$

O conceito de solidariedade é pressuposto fundamental para o desenvolvimento de uma preocupação presente na obra de Durkheim que é a formação da consciência coletiva. A consciência coletiva só existe em função das crenças e dos sentimentos presentes nas consciências individuais. Porém, distingue-se destas últimas, pois evolui segundo suas próprias leis e não é apenas a expressão ou o efeito das consciências individuais. Nas sociedades dominadas pela solidariedade mecânica, a consciência coletiva abrange a maior parte das consciências individuais. Ao mesmo tempo, quando reina a solidariedade orgânica ocorre uma redução da esfera da existência que cobre a consciência coletiva, um enfraquecimento das reações coletivas contra a violação das proibições e, sobretudo maior na interpretação individual dos imperativos sociais.

Durkheim entende que o indivíduo nasce da sociedade, e não a sociedade nasce do indivíduo. O primado da sociedade sobre o indivíduo tem pelo menos dois sentidos, que no fundo nada tem de paradoxal. O primeiro é o da prioridade histórica das sociedades em que os indivíduos se assemelham uns aos outros e estão, por assim dizer, perdidos do todo, com relação àquelas sociedades cujos membros adquiriram ao mesmo tempo consciência da sua responsabilidade e da capacidade que têm de exprimi-la. O segundo baseado numa prioridade lógica de explicação dos fenômenos sociais. Se a solidariedade mecânica precedeu a solidariedade orgânica, não se pode, com efeito, explicar os fenômenos da diferenciação social e da solidariedade orgânica a partir dos indivíduos. A consciência da individualidade não pode existir antes da solidariedade orgânica e da divisão do trabalho. A busca racional do aumento da produção não pode explicar a diferenciação social, pois esta pressupõe tal diferenciação social. (Aron, 2002)

A divisão do trabalho é estrutura de toda a sociedade, de que a divisão técnica ou econômica do trabalho não passa de uma manifestação. Durkheim afirma que para definir cientificamente a divisão do trabalho, é necessário estudá-la melhor. Para estudar cientificamente um fenômeno social, é preciso estudá-lo objetivamente, isto é, do exterior, encontrando o meio pelo qual os estados de consciência não perceptíveis diretamente podem ser reconhecidos e compreendidos. Estes são os fenômenos jurídicos. (Aron, 2002)

Durkheim caracteriza como tipos de solidariedade: o direito repressivo, que pune as faltas ou crimes e o direito cooperativo, cuja essência não é a punição das violações das regras sociais, mas organizar a cooperação entre os indivíduos. O direito repressivo revela a consciência coletiva nas sociedades de solidariedade mecânica. Quanto maior é a consciência coletiva, mais forte e particularizada, maior será o número de atos considerados como crimes. Atos que violam um imperativo que ferem diretamente a consciência da coletividade. O crime é um ato proibido pela consciência coletiva e só pode ser definido do exterior tomando como referência o estado de consciência coletiva da sociedade considerada. $\mathrm{O}$ criminoso não é aquele que consideramos culpado com relação a 
Deus, e nem através dos nossos valores. Criminoso é aquele que, numa sociedade determinada, deixou de obedecer às leis do Estado. (Aron, 2002)

Durkheim esboçou uma teoria do crime, deduzindo uma teoria das sanções. A sanção não tem a função de amedrontar ou de dissuadir, mas sim satisfazer a consciência comum, ferida por um ato cometido por um dos membros da coletividade. Ela exige reparação e o castigo do culpado e esta reparação feita aos sentimentos dos outros. No direito cooperativo, por sua vez, não se trata de punir, mas sim restabelecer o estado das coisas como deve ser segundo a justiça.

Durkheim afirma que a sociedade moderna não se baseia no contrato, bem como a divisão do trabalho não se explica a partir de decisões racionais dos indivíduos. Apesar de reconhecer a importância dos contratos, afirma que o elemento contratual é um derivado da estrutura da sociedade, e até mesmo um derivado do estado de consciência coletiva na sociedade moderna. Os contratos estão situados dentro de um contexto social que não é determinado pelos indivíduos. A divisão do trabalho pela diferenciação é a condição primordial da existência de uma esfera do contrato. A sociedade em que predomina o tipo orgânico de solidariedade se define prioritariamente pela diferenciação social, de que o contratualismo é uma consequiência e manifestação. É a partir da sociedade global que compreendemos quem são os indivíduos e como eles podem livremente contratar entre si.

A causa do desenvolvimento da divisão do trabalho nas sociedades modernas é um fenômeno essencialmente social. Tendo como referência o princípio da causa e do efeito, a causa deve ser também social, eliminando a explicação individualista. Neste sentido, Durkheim afasta-se da explicação de Augusto Comte segundo o qual o desenvolvimento social seria o enfado ou a procura da felicidade. Para Durkheim, nada prova que nas sociedades modernas os homens sejam mais felizes do que nas sociedades arcaicas. A diferenciação social não pode ser explicada pela busca do prazer ou da felicidade. (Aron, $2002)^{6}$

Durkheim apresenta o fenômeno do suicídio como a prova maior de que a felicidade não aumenta com o progresso. O suicídio é maior nas sociedades modernas do que as do passado. O livro que Durkheim escreveu sobre o suicídio está estreitamente ligado ao estudo da divisão do trabalho (O Suicídio - 1897). Durkheim aprova a divisão orgânica do trabalho que considera um desenvolvimento normal do capitalismo. Aprova a diferenciação dos indivíduos em profissões; a regressão da autoridade da tradição; o domínio crescente da razão. Contudo, afirma que os homens não estão mais felizes na sociedade moderna, expressão que comprova com o aumento dos suicídios. Discute o conceito de anomia, ausência ou desintegração das normas sociais, conceito que vai ter um papel predominante no estudo do suicídio. Analisa as crises econômicas, a inadaptação dos trabalhadores e suas ocupações, a violência das reivindicações dos indivíduos com relação à coletividade.

Todos os fenômenos citados anteriormente são patológicos. Na medida em que as sociedades modernas se fundamentam na diferenciação, torna-se indispensável que o trabalho que cada um exerce corresponda a seus desejos e aptidões. A sociedade que propicia o crescimento do individualismo está obrigada a respeitar a justiça. Se os valores comuns de uma sociedade se debilitam, a sociedade fica ameaçada de desintegração. $\mathrm{O}$ problema central das sociedades modernas é as relações entre os indivíduos e o grupo. $\mathrm{O}$ homem tornou-se por demais consciente de si mesmo para aceitar cegamente os imperativos sociais. O individualismo comporta perigos, pois o indivíduo pode exigir da coletividade mais do que a mesmo pode dar. Durkheim defende que é necessária uma disciplina que só a sociedade pode impor. A organização de grupos profissionais que favoreçam a integração dos indivíduos à sociedade é a solução para esse problema. 
O estudo do suicídio trata de um processo patológico das sociedades modernas, e revela de forma mais marcante a relação entre o indivíduo e a sociedade. Durkheim demonstra até que ponto os indivíduos são determinados pela realidade coletiva. Com efeito, o fenômeno suicídio é central, pois nada é mais individual do que um homem tirar a sua própria vida. O suicídio é todo o caso de morte provocado diretamente ou indiretamente por um ato positivo ou negativo realizado pela própria vítima e que ela sabia que devia provocar esse resultado. O conceito de suicídio engloba não só casos reconhecidos por todos, como também os casos de morte voluntária envolta em auréola de heroísmo e de glória.

A taxa de suicídio é característica de uma sociedade global, ou de uma região ou uma província. O mais importante é a relação entre o fenômeno individual - o suicídio - e o fenômeno social - a taxa de suicídio. Durkheim afasta as explicações de tipo psicológico. Até admite a sua existência, mas centraliza as suas discussões no social. As causas do suicídio não são psicológicas, mas sociais. A taxa de suicídio varia de acordo com algumas circunstâncias que examina. Acredita que é possível determinar tipos sociais de suicídio em função de determinadas correlações estatísticas. Com efeito, denomina três tipos de suicídio que são: egoísta, altruísta e o anômico. (Aron, 2002)

O suicídio egoísta é analisado graças à correlação entre a taxa de suicídio e os contextos sociais integradores, como a religião e a família. A taxa de suicídio varia de acordo com a idade, é maior nos homens do que nas mulheres, e muda de acordo com a religião. Baseando-se em estatísticas alemãs, discute que o mesmo é maior nas populações protestantes do que nas católicas. Os indivíduos deixados a si mesmo têm desejos infinitos. Incapazes de serem satisfeitos, só atingem certo equilíbrio graças a uma força exterior de ordem moral, que lhes ensina a moderação e os ajuda a encontrar a paz. Homens e mulheres são mais inclinados ao suicídio quando pensam essencialmente em si mesmos, quando não estão integrados ao grupo social, quando os desejos que os animam não podem ser reduzidos a uma medida compatível com o destino humano pela autoridade do grupo e pela força da obrigação. O suicídio altruísta é aquele em que o indivíduo se mata devido a imperativos sociais, sem pensar em fazer valer seu direito à vida. Um dos exemplos são os suicídios no Exército. O suicídio anômico é o característico das sociedades modernas, o que mais interessou a Durkheim. Ele é revelado pela correlação estatística entre a frequência do suicídio e as fases do ciclo econômico. Durkheim observa que a sua taxa cresce nos períodos de crise econômica e também naqueles de grande prosperidade. Porém, ocorre sua redução nos períodos de grandes acontecimentos políticos. O que lhe interessa é a crise da sociedade moderna definida pela desintegração do social e pela debilidade dos laços que unem o indivíduo ao grupo. O suicídio anômico atinge os indivíduos em função das condições de vida da sociedade moderna, em que a existência do social não é regulamentada pelos costumes. Os indivíduos estão em constante competição uns com os outros; esperam muito da vida, fazem grandes exigências e se sentem sempre acuados pelo sofrimento resultante da desproporção entre suas aspirações e satisfações.

O suicídio egoísta se manifestará pela apatia e pela ausência de vinculação com a vida; o altruísta pela energia e a paixão; o anômico pela irritação associada às numerosas situações de decepção oferecidas pela vida moderna, por um desgosto resultante da tomada de consciência da desproporção entre as aspirações e as satisfações.

Os suicídios são fenômenos individuais, cujas causas são, contudo, essencialmente sociais. As circunstâncias sociais que criam o suicídio criam também as predisposições psicológicas, porque os indivíduos, vivendo em condições peculiares da sociedade moderna, são mais sensíveis e, por conseguinte, mais vulneráveis. As causas sociais dos suicídios são as forças sociais que variam de sociedade para sociedade, de grupo para 
grupo e de religião para religião. As sociedades são de natureza diferente das dos indivíduos. Existem fenômenos e forças cujo suporte é a coletividade e não a soma dos indivíduos. Há fenômenos sociais específicos que comandam os fenômenos individuais; o exemplo mais notável são as correntes sociais que levam os indivíduos à morte, embora cada um deles pense que está obedecendo a si mesmo, quando na realidade é joguete das forças coletivas. (Aron, 2002)

Durkheim afirma em "As Regras do Método Sociológico" que o crime é, pois necessário; ele se liga às condições fundamentais de toda a vida social e, por isso mesmo, tem sua utilidade; pois estas condições de que é solidário são, elas próprias, indispensáveis à evolução normal da moral e do direito. Durkheim considera o crime um fenômeno socialmente normal, o que não significa que os criminosos não devam ser punidos. $\mathrm{O}$ crime não é um fenômeno patológico, bem como, certa taxa de suicídio é considerada como normal. O patológico é voltado para o aumento da taxa de suicídios que se caracteriza pelo aumento da diferenciação social, a densidade da população, a intensidade das comunicações e a luta pela vida. Quando o indivíduo não é integrado na sociedade, afirmação presente na "Divisão do Trabalho Social" e em "O Suicídio", é que se constitui em um caso patológico. A única forma de integrar o indivíduo à sociedade é através da profissão, do trabalho. É através da divisão do trabalho, da profissão hierarquizada e da disciplina que os homens conseguem visualizar aquilo que são.

Durkheim discute em "O Suicídio" que o homem individual é um homem de desejos e, por isso, a primeira necessidade da moral e da sociedade é a disciplina. ${ }^{7} \mathrm{O}$ homem precisa ser disciplinado por uma força superior, autoritária e amável, isto é, digna de ser amada. Esta força, que ao mesmo tempo se impõe e atrai, só pode ser a própria sociedade. Durkheim afirma em As regras do método sociológico que é preciso que a autoridade de que goza a consciência moral não seja excessiva; de outra maneira, ninguém ousaria levantar a mão contra ela e ela se cristalizaria facilmente numa forma imutável.

Para as sociedades e para os indivíduos, a doença é algo que deve ser evitado. A ciência é o caminho para evitá-la. Não se trata de perseguir um fim que foge à medida que se avança, mas de trabalhar para manter o estado normal, restabelecendo o perturbado. $\mathrm{O}$ dever do homem do Estado, tendo como ferramenta a ciência, é executar o papel do médico: por meio de uma boa higiene, previne a eclosão das doenças, e, quando estas se declaram, procura saná-las. ${ }^{8}$

O terceiro grande livro de Durkheim “As Formas Elementares da Vida Religiosa" é uma das suas obras mais importantes e contundentes. Seu objetivo é elaborar uma teoria geral da religião, com base na análise das religiões mais simples e primitivas. A ciência detém, nas sociedades modernas individualistas e racionalistas, a autoridade intelectual e moral suprema. É possível ir além da ciência, não permanecer atrás e recusar os seus ensinamentos. Mas a sociedade moderna, como todas as sociedades têm necessidade de crenças comuns. A ciência da religião revela a possibilidade de reconstruir as crenças necessárias ao consenso, não porque seja suficiente para fazer surgir a fé coletiva, mas porque deixa a esperança de que a sociedade do futuro ainda seja capaz de fabricar deuses, uma vez que todos os deuses do passado não foram senão a transfiguração da própria sociedade. A ciência não recria uma religião, mas dá confiança na capacidade que têm as sociedades de produzir em cada época os deuses que necessitam. Os interesses simbólicos não passam da forma simbólica de interesses sociais e morais. Durkheim afirma com relação à ciência da religião que depois de matar os deuses transcedentes a humanidade amaria a si mesma, ou seja, aquilo que ela tinha de melhor. (Aron, 2002)

Durkheim acredita que a essência da religião é a divisão do mundo em fenômenos sagrados e profanos. Não é a crença numa divindade transcendente, pois existem religiões, 
mesmo superiores, sem Deus. O Budismo é um exemplo. A religião também não pode ser definida pelas noções de mistério ou sobrenatural. Só se concebe o sobrenatural por oposição ao natural, que só é possível de maneira positiva e através da ciência. O sagrado se compõe de um conjunto de coisas, de crenças e de ritos. A religião pressupõe o sagrado, em seguida a organização das crenças relativas ao sagrado e, por fim, ritos ou práticas derivados das crenças. Durkheim acredita poder explicar a realidade do fenômeno religioso. Se o homem adora a sociedade transfigurada, adora de fato uma realidade autêntica. A religião é uma experiência por demais permanente e profunda para não corresponder a uma realidade autêntica. Se esta realidade autêntica não é Deus, é preciso que seja o que está situado, por assim dizer, imediatamente abaixo de Deus, a sociedade.

O objetivo da teoria da religião de Durkheim é fundamentar o objeto da fé, sem admitir o conteúdo intelectual das religiões tradicionais, condenadas pelo desenvolvimento do racionalismo científico; este permite salvar o que parece destruir, demonstrando que os homens nunca adoram senão a sua própria sociedade. A sociedade desperta o sentimento do divino responsável pelo respeito, devotamento e a adoração. A sociedade favorece também o surgimento de crenças, porque os indivíduos vivem em comunhão uns com os outros e, na efervescência da festa, adquirem a capacidade de criar o divino. A sociedade é uma máquina de criar deuses, acredita Durkheim. Mas para que este esforço de criação tenha êxito, é preciso que os indivíduos escapem da vida cotidiana, saiam de si mesmos, sejam possuídos pelo fervor de que a exaltação da vida coletiva é causa e expressão. As sociedades são levadas a criar deuses ou religiões quando entram em estado de exaltação que resulta da intensificação extrema da própria vida coletiva. ${ }^{9}$

Toda essa reflexão fundamenta o sentido da sociologia enquanto ciência, a busca de explicações científicas para um processo de vida em sociedade crescente. É assim que em "As Regras do Método Sociológico", Durkheim afirma que a sociologia é o estudo dos fatos essencialmente sociais e a explicação desses fatos de maneira sociológica. Sua concepção baseia-se em uma teoria dos fatos sociais. Seu objetivo é demonstrar que é possível existir uma sociologia científica e objetiva, conforme o modelo das outras ciências naturais.

A característica do fato social é que ele exerce uma coerção sobre os indivíduos. Os fatos sociais são coisas, e as coisas são tudo o que nos é dado, tudo o que se oferece à observação. O fato social é toda a maneira de fazer, suscetível de exercer uma coerção externa sobre o indivíduo. ${ }^{10}$ Os pressupostos apresentados anteriormente são fundamentais para o entendimento e recuperação do pensamento educacional de Durkheim.

\section{O pensamento educacional de Durkheim}

As discussões sobre a educação são parte importante da obra de Durkheim. As reflexões sobre uma sociedade acabada, a mais avançada da história da humanidade, proporcionam a elaboração de fundamentos educacionais voltados à construção de uma moral coletiva, condição essencial para a existência da solidariedade orgânica na sociedade. É assim que em "Educação e Sociologia" Durkheim afirma que a influência das coisas sobre os homens é diversa daquela que provém dos próprios homens; e a ação dos membros de uma geração sobre os outros, difere da que os adultos exercem sobre as crianças e os adolescentes. É esta relação que Durkheim denomina como Educação.

Tomando como referência os princípios da solidariedade orgânica baseada nas diferenças entre os homens, tal qual afirmamos anteriormente, Durkheim entende em "Educação e Sociologia" que nem todos os homens são feitos para refletir; será preciso que sempre haja homens de sensibilidade e homens de ação. Os homens não podem dedicar, todos, ao mesmo gênero da vida; existem diferentes funções a preencher. É preciso 
construir uma harmonia para o trabalho. A educação é em essência, um fenômeno social que consiste em socializar os indivíduos. Educar uma criança é prepará-la (ou forçá-la) a participar de uma ou de várias comunidades. A educação é um processo social, e cada sociedade tem as instituições pedagógicas que lhe convém. Todo o passado da humanidade contribui para estabelecer o conjunto de princípios que dirigem a educação do presente.

Durkheim afirma ainda que para definir a educação será preciso considerar os sistemas educativos que existem, ou tenham existido, compará-los e aprender deles os caracteres comuns. Para que haja educação é necessário que haja uma geração de adultos e de jovens, crianças e adolescentes, em que uma ação seja exercida da primeira sobre a segunda. Não há povo em que não exista certo número de idéias, sentimentos e práticas que a educação deve inculcar nas crianças, independente da categoria social a que pertençam. Toda e qualquer educação, seja a dos ricos ou a dos pobres, tem objetivo de fixar idéias nas cabeças dos educandos. Resulta destes fatos que cada sociedade faz do homem certo ideal, tanto do ponto de vista intelectual, quando do físico e moral, um ideal que de certo ponto é o mesmo para todos os homens. Esse ideal, ao mesmo tempo uno e diverso, é que constitui a parte básica da educação. ${ }^{11}$

A educação assegura a diversidade, permitindo especializações. A especialização do trabalho provoca nas crianças sobre um primeiro fundo de idéias e de sentimentos comuns. Com efeito, a educação é para a sociedade o meio pela qual ela prepara, no íntimo das crianças, as condições essenciais da própria existência. A educação, entende Durkheim, é a ação exercida pelas gerações adultas sobre as gerações que não se encontrem ainda preparadas para a vida social, tendo por objetivo suscitar e desenvolver, na criança, certo número de talentos físicos, intelectuais e morais, reclamados pela sociedade política, no seu conjunto, e pelo meio especial a que a criança, particularmente se destine.

Durkheim em "A Educação Moral" aponta que as crianças não fariam senão reproduzir um traço das sociedades primitivas. Como os selvagens, as crianças estão sob o domínio das paixões que as torna impotentes à contenção. É preciso constituir através da educação os estágios originais que não estão formados nas crianças. A criança pertence ao domínio das paixões e habita entre os selvagens. Entre ela e os adultos normais há o fosso da mais radical dicotomia e polarização. Há que sufocar e cortar a sua curiosidade, sua mobilidade, vivacidade e imaginação. Há que instigar a obediência que o dispositivo pedagógico transformará em espírito de disciplina. Suas tendências serão vigiadas, medidas, avaliadas, instigadas e fortalecidas aos moldes do adulto civilizado.

A disciplina não visa estimular na criança o desejo de instruir-se, nem é um procedimento voltado para poupar forças do educador. Sua verdadeira função é atuar como um instrumento moral. A moralidade da classe depende da firmeza do mestre, e uma classe indisciplinada é um perigo moral porque a efervescência é coletiva. A complacência com a fraqueza infantil esquece que as crianças são as primeiras a sentirem-se bem com uma boa disciplina porque, como os povos, são felizes quando se sentem bem governadas. Durkheim afirma em "A Educação Moral" que a ausência de disciplina produz confusão e sofrimento de não saber o que é o bem, nem o que é o mal; o que se deve fazer e o que não se deve; o que é lícito e o que é ilícito. Em uma classe bem disciplinada não há nem confusão, nem o sofrimento, mas a saúde e o bom humor. Cada aluno está em seu lugar e sente-se bem onde está.

A teoria da educação de Durkheim se inspira em uma concepção de homem. O homem é dominado pelo egoísmo natural, animado de desejos infinitos, tendo necessidade, portanto, de ser disciplinado. Durkheim afirma em Educação e Sociologia que para aprender a conter o egoísmo natural, subordiná-lo a fins mais altos, submeter os desejos ao 
império da vontade, conformá-los com justos limites, será preciso que o educando exerça sobre si mesmo grande trabalho de contenção. A educação consiste em habituar os indivíduos a uma disciplina, a qual deve ter, e não pode deixar de ter, um caráter autoritário. Formar os indivíduos, tendo em vista a integração na sociedade, é torná-los conscientes das normas que devem orientar a conduta de cada um e do valor imanente e transcendente das coletividades que cada homem pertence ou deverá pertencer. A educação visa criar no homem um ser novo.

A educação satisfaz, antes de tudo, a necessidades sociais. Durkheim afirma que se os indivíduos só agem segundo as necessidades sociais, parece que a sociedade impõe aos homens insuportável tirania. Os homens são interessados nessa submissão; porque o ser novo que a ação coletiva, por intermédio da educação edifica representa o que há de melhor e mais humano nos homens. Desejando melhorar a sociedade, o indivíduo melhora a si mesmo. A ação exercida pela educação não tem por objeto comprimir o indivíduo, amesquinhá-lo, desnaturá-lo, mas ao contrário, engrandecê-lo e torná-lo humano. ${ }^{12}$

O Estado tem importante papel na educação. Se a educação apresenta-se como função coletiva, se tem por fim adaptar a criança ao meio social para a qual se destina, é impossível que a sociedade se desinteresse pelo trabalho. Se a sociedade não estiver sempre presente e vigilante, para obrigar a ação pedagógica a exercer-se em sentido social, essa se porá ao serviço de interesses particulares e a grande alma da pátria se dividirá, esfacelando-se numa multidão incoerente de pequenas almas fragmentárias, em conflito uma com as outras. É assim que Durkheim afirma que é preciso que a educação assegure uma comunidade de idéias e sentimentos, sem o qual nenhuma sociedade sobrevive. Com efeito, admitindo que a educação seja função social, não pode os Estado dela se desinteressar. Tudo o que é educação deve ser submetido a sua influência. Isto não quer dizer que o Estado deva monopolizar o ensino. $\mathrm{O}$ fato de deixar abrir escolas que não sejam as suas, não se segue o fato de que deva tornar-se estranho ao que nelas venha a passar. A educação privada deve estar sob seu juízo e fiscalização.

As afirmações durkheiminianas referentes à sociedade e a educação nos oferecem questionamentos quanto à importância em termos da formação dos homens do presente para o futuro. Estariam elas superadas - apesar dos modismos de novas teorias educacionais, "os ismos de dez em dez anos" adotados no Brasil sem que a maioria dos educadores sequer as conheçam - ou ainda existentes? Qual influência epistemológica norteia as reflexões de muitos profissionais da educação defensores de que as teorias não se relacionam com a prática? Os debates continuam.

\section{Referências}

ARON, Raymond. Etapas do Pensamento Sociológico. SP: Martins Fontes, 2002.

BRAVERMAM, H. Trabalho e Capitalismo Monopolista.Rio de Janeiro: Zahar, 1980. 379p.

DURKHEIM, E., Da divisão do trabalho social. [tradução Eduardo Brandão]. $2^{\circ}$ ed. São Paulo: Martins Fontes, 1999.

. O suicídio. SP: Martins Fontes, 2000

. As regras do método sociológico. São Paulo, Ed. Martin Claret, 2002.

As formas elementares da vida religiosa". IN: Os pensadores. 2 ed. São

Paulo: Abril Cultural, 1983.

Educação e Sociologia. SP; Melhoramentos, 1952.

Moral Education. New York: The Free Press, 1971.

HOBSBAWM, Eric. J. A Era do Capital 1848 - 1875. Rio de Janeiro: Paz e Terra, 1997. 459p. 
Companhia de Letras, 1998. 598p.

A Era dos Impérios 1875 -1914; Tradução Sieni Maria Campos e

Yolanda Steidel de Toledo. Rio de Janeiro: Paz e Terra, $1988.546 \mathrm{p}$.

LÊNIN, Vladimir Ilich - O imperialismo: fase superior do capitalismo. tradução Olinto

Beckerman. 4. ed. - São Paulo: Global, 1987. 127p.

LUCENA, Carlos. Hayek: liberalismo e formação humana. Campinas, SP: Alínea, 2010

Tempos de destruição: educação, trabalho e indústria do petróleo no

Brasil. Campinas: Autores Associados; Uberlândia: EDUFU, 2004.

MARX. K. . Sobre o suicidio. SP: Boitempo Editorial, 2006.

MELLO, A. F. Marx e a globalização. São Paulo: Boitempo Editorial, 1999. 286p.

Data de Recebimento: 10 de outubro de 2010

Data do Parecer: 18 de novembro de 2010

\begin{abstract}
${ }^{1}$ Cientista Social. Doutor em Filosofia e História da Educação. Professor do PPGED/FACED/UFU. Pósdoutorando em Educação pelo Departamento de Educação da UFsCAR. Bolsista de Produtividade do CNPQ.

${ }^{2}$ Os países europeus começaram a fazer alianças políticas e militares desde o final do século XIX. Durante o conflito mundial estas alianças permaneceram. De um lado havia a Tríplice Aliança formada em 1882 por Itália, Império Austro-Húngaro e Alemanha ( a Itália passou para a outra aliança em 1915). Do outro lado a Tríplice Entente, formada em 1907, com a participação de França, Rússia e Reino Unido. Em 1917 ocorreu um fato histórico de extrema importância: a entrada dos Estados Unidos no conflito. Os EUA entraram ao lado da Tríplice Entente, pois havia acordos comerciais a defender, principalmente com Inglaterra e França. Este fato marcou a vitória da Entente, forçando os países da Aliança a assinarem a rendição. Os derrotados tiveram ainda que assinar o Tratado de Versalhes que impunha a estes países fortes restrições e punições. A Alemanha teve seu exército reduzido, sua indústria bélica controlada, perdeu a região do corredor polonês, teve que devolver à França a região da Alsácia Lorena, além de ter que pagar os prejuízos da guerra dos países vencedores. A guerra gerou aproximadamente 10 milhões de mortos, o triplo de feridos, arrasou campos agrícolas, destruiu indústrias, além de gerar grandes prejuízos econômicos.
\end{abstract}

http://www.suapesquisa.com/primeiraguerra/ acesso dia 8/03/2011 14 horas.

${ }^{3}$ Ler Carlos Lucena. Hayek: liberalismo e formação humana. Campinas, SP: Alínea, 2010

${ }^{4}$ De acordo com Hobsbawm (1997), no início da década de 1870, a expansão econômica e o liberalismo pareciam irresistíveis. A era do triunfo liberal atingia uma depressão generalizada. Uma crise que se instalou em virtude de uma superprodução de mercadorias voltada para um mercado restrito. $\mathrm{O}$ mercado não conseguia acompanhar o desenvolvimento da produção de produtos, o que levou a uma drástica redução dos preços, atingindo diretamente a lucratividade do capital. A queda de preço das mercadorias representou um desastre para os produtores e um benefício, em princípio, àqueles que podiam consumir. A Grande Depressão colocou fim ao longo reinado do liberalismo econômico, anunciando a falência do mercado auto-regulado. Entre as saídas apontadas para a crise, estava a necessidade de renovação dos estoques de matérias primas, fundamentais para o funcionamento do capitalismo. Por volta de 1868, o capitalismo monopolista se instaura em um processo de grande transformação, caracterizando-se pelo processo de centralização de capitais e a formação entre outros, de grandes empresas monopolistas denominadas cartéis, consórcios de capitais, sociedades anônimas, etc. O Capital internacional financiou a formação de uma estrutura político administrativa que tornasse possível esse tipo de sociedade de consumo de mercadorias.

O capitalismo iniciou o seu período monopolista, marcado por um aumento da opressão e da dependência. De acordo com Hobsbawm (1988) entre 1880 a 1914, a maior parte do planeta, à exceção da Europa e da América, foi dividida em territórios sob governo direto ou dominação política de um ou outro Estado de um pequeno grupo. Esses Estados, principalmente Grã Bretanha, França, Alemanha, Itália, Holanda, Bélgica, EUA e Japão exerceram um domínio político e econômico nos antigos impérios europeus pré-industriais sobreviventes da Espanha e de Portugal. Lênin (1987) afirma que, por volta de 1914, as quatro maiores potências do planeta adquiriram 14,1 milhões de quilômetros quadrados de colônias, ou seja uma superfície quase vez e meia maior que a da Europa, com uma população de aproximadamente 100 milhões de habitantes.

${ }^{5}$ Nas sociedades antigas, o indivíduo não vem historicamente em primeiro lugar. A tomada de consciência da individualidade decorre do próprio desenvolvimento histórico. 


\footnotetext{
${ }^{6}$ Essa afirmação justifica as preocupações de Durkheim quanto aos rumos da sociedade expressa na parte anterior deste trabalho. O que nos parece primordial é perceber a justificativa do ajuste social como saída para a sociedade. Como não se comprova que as sociedades atuais sejam mais felizes do que as antigas, restanos perguntar se a felicidade é possível dentro de uma sociedade baseada na exploração do homem pelo homem. A construção do consenso social como alternativa para a elaboração da felicidade humana é uma tese que não se comprova.

${ }^{7}$ Marx oferece outra interpretação para o fenômeno do suicídio. Marx Em obra denominada "Sobre o suicídio" publicada em 1846 com o título original "Peuchet: sobre o suicídio", apontou que a diversidade das suas causas parece escapar à censura uniforme e insensível dos moralistas.. [...] Como se explica que, apesar de tantos anátemas, o homem se mate? É que o sangue não corre do mesmo modo nas veias de gente desesperada e nas veias de seres frios, que se dão o lazer de proferir palavrório estéril. (...) o suicídio não é mais do que um entre os mil e um sintomas da luta social geral, sempre percebida em fatos recentes, da qual tantos combatentes se retiram porque estão cansados de serem contados entre as vítimas ou porque se insurgem contra a idéia de assumir lugar honroso entre os carrascos. (Marx, 2006, p. 23-9)

${ }^{8}$ Aqui se explica a admiração do nazismo pela obra de Durkheim. A exclusão de concepções de mundo diferentes, entendidas como doenças sociais. A repressão histórica dos movimentos sociais e suas justificativas tem seus princípios nestas afirmações.

${ }_{9}^{9}$ Esta é uma preocupação presente em todos os discípulos do iluminismo no período. É assim que Weber afirma o desenvolvimento de uma ética protestante como fundamental para o avanço do capitalismo. Feuerbach afirmar que o Deus da religião cristã não é outra coisa que o conjunto dos atributos do homem que, não podendo ser realizados, nem reconhecidos na vida real, são projetados pelo homem fora de si na forma de um ser imaginário. Hegel defender que o homem converte seus pensamentos e sentimentos em Deus; converte sua essência e seu ponto de vista em essência e ponto de vista de Deus. Marx demonstrar que o assim como na religião o homem está dominado pelas obras do seu próprio cérebro, na produção capitalista está pelas obras das suas próprias mãos..

${ }^{10}$ A moda é um exemplo. Não é o indivíduo que a origina, é a sociedade que se manifesta por meio de obrigações implícitas e difusas. As instituições da Educação, o direito, as crenças são dados também exteriormente aos indivíduos.

${ }^{11}$ Ele tem como objetivo suscitar na criança: a) Um número de estados físicos e mentais, que a sociedade considere como indispensáveis a todos os seus membros. b) Estados físicos e mentais que o grupo social considere igualmente indispensável a todos os quantos o formem.

${ }^{12}$ Durkheim entende que os homens não desejam a ciência senão na medida em que a experiência lhes tenha demonstrado que não podem passar sem ela. O homem não veio conhecer a sede do saber senão quando a sociedade a despertou; e a sociedade não a despertou senão quando sentiu que seria necessário fazê-lo. Isso ocorreu quando a vida social tornou-se complexa em demasia, que não poderia funcionar de outro modo que não fosse pelo pensamento refletido, isto é, pelo pensamento esclarecido pela ciência.
} 